\title{
The effect of continuous and pulsed current on microstructure and mechanical properties in TIG welding of Al-Si alloy sheets
}

\author{
A. Durgutlu*
}

Gazi University, Department of Metallurgy \& Materials Engineering, 06500 Ankara, Turkey

Received 27 April 2015, received in revised form 14 December 2015, accepted 11 January 2016

\begin{abstract}
In this experimental study, Al-Si alloy sheets were joined through TIG welding method by using continuous current and pulsed current. Tensile test, bending test, hardness test, and microstructure examination of joined test samples were carried out in order to see the effect of current type on mechanical properties of welded samples. Experimental results showed that pulsed current led to low heat input, grain refinement, and hardness increase in weld metal compared to alternative current. The samples joined by using the pulsed current showed higher tensile strength than the samples welded by using the alternative current. After bending test, cracks, tearing, and surface defection were not observed in the samples.
\end{abstract}

K e y words: aluminium, TIG welding, current type, mechanical properties

\section{Introduction}

Today's needs have directed industrial production towards alternative materials which are lighter and have high electrical and thermal conductivity such as aluminium [1]. Aluminium materials are primary among these materials. In the joining of aluminium and its alloys, TIG welding is generally preferred since it is economical and easy to apply. Usage of aluminium alloys in various constructions has gradually increased in the recent times. Primary ones of these applications can be listed as the automotive industry, rail vehicles, bridges, marine structures due to their resistance to corrosion, high-speed sea vessels, space vehicles, and pressure vessels. In all these applications, welding is the principal joining method and the strength is the main factor $[2-6]$.

Considering the mechanical properties of the joined materials, factors such as welding process, filler metal, heat input, and a number of welding passes affect the microstructure of welded joint, change the width of the heat affected zone, and lead to residual stresses on base metal $[7,8]$. Butt-welding is one of the commonly used methods in many constructions and manufacturing processes. Behaviour of butt-welded joints, which have a wide area of usage, under different loads is one of the subjects investigated by researchers $[2,9]$.

Melting zone of welding seam generally contains coarse and columnar grains due to temperature conditions during solidification of weld metal. This result generally reduces mechanical properties of welding seam and hot cracking resistance. Therefore, control of solidification microstructure of welding seams is generally the desired situation even though it is difficult due to very high temperature and temperature differences. Furthermore, a few methods have been successfully applied for grain refinement in the weld metal since the past. These methods can be listed as physical mixture techniques such as heterogeneous nucleation through inoculation, the addition of microparticle, commencing of solidification from the surface through gas flushing on the surface, and torch vibration [10-13]. As a result of the development of machines generating pulsed current in the recent times, researchers have also started to examine effects of pulsed current on grain structure of weld metal in different materials [14-19].

High and low current values during welding process as well as pulsed current parameters involving duration of these values and pulse frequency significantly affect arc stability, welding quality, the appearance of welding seam, and welding seam geometry.

*Corresponding author: tel.: +90 312 2028767; fax: +90 312212 0059; e-mail address: durgutlu@gazi.edu.tr 
Table 1. Parameters used in the joining process

\begin{tabular}{lcc}
\hline Process & Continuous current & Pulsed current \\
\hline Tungsten electrode diameter (mm) & 2.4 & 2.4 \\
Filler wire diameter (mm) & 2 & 2 \\
Voltage (V) & 28 & 28 \\
Current (A) & 140 & - \\
Peak current (A) & - & 140 \\
Base current (A) & - & 60 \\
Pulse frequency (Hz) & - & 50 \\
Pulse on time (\%) & Argon & 14 \\
Shielding gas & 14 & 140 \\
Gas flow rate $\left(\mathrm{lmin}^{-1}\right)$ & 140 & 1.26 \\
Welding speed $\left(\mathrm{mm} \mathrm{min}^{-1}\right)$ & 1.68 & Argon \\
Heat input (kJ mm &
\end{tabular}

Pulsed arc is formed by the fact that welding current rapidly increases and decreases between high current and low current. It seems overlapping the centres on the weld line. Improper selection of these parameters may cause primarily irregular surface appearance of the seam and then melt cavities, undercuts, and inadequate penetration. Therefore, in order to achieve a good welding, proper selection of pulsed current parameters is very important. Since pulsed current parameters are interconnected and complicated during the welding process, these parameters are required to be compatible with each other in order to achieve an acceptable welded joint [1, 20-22].

Effects of pulsed current on grain refinement and mechanical properties in melting zone of welded joints have recently been examined by numerous researchers on different materials [23-25]. In this study, 4000 series aluminium sheets were joined through TIG welding method by using both continuous and pulsed currents. Microstructure, tensile strength, hardness, and bending properties of the joints were examined.

\section{Material and method}

In this experimental study, a $3-\mathrm{mm}$ thick rolled product, which was AA 4000 (Al-Si alloy) series aluminium sheet with the silicon rate of $8.5 \%$, was joined through the TIG welding method by using different types of current (continuous and pulsed current). The TAL-4047 (SG-A1Si12) aluminium wire was used as the additional metal in the study. After aluminium pieces to be joined were prepared in sizes of $220 \times 120 \times 3 \mathrm{~mm}^{3}$, their surfaces were cleaned and butt-welded with a distance of $2 \mathrm{~mm}$ between them. The sheets were joined as single-pass on a substrate and left to cool in the open air. The joining processes were conducted by using the inverter welding machine under argon shielding gas atmosphere. Table 1 illustrates welding parameters used in the experiments.

The samples were prepared from the welded sheets for tensile, hardness, and microstructure examinations. After the microstructure samples had been bakelited, they were subject to standard metallographic sample preparation process. Then, the samples were etched with an etchant which contained $0.5 \%$ hydrofluoric acid $(0.5 \mathrm{HF}+99.5$ distilled water $)$ solution. Microstructural images of necessary points of the prepared samples were taken by using an optical microscope connected to a digital camera. The microstructure samples were also used for hardness measurements. The hardness measurements were performed by using a Vickers microhardness testing device under a load of $0.5 \mathrm{~kg}$. The tensile samples were processed and prepared by using the CNC milling machine in accordance with ASTM E8M. Tensile processes applied to joints were performed at the feed rate of $2 \mathrm{~mm} \mathrm{~min}^{-1}$.

\section{Results and discussion}

As a result of the experiments, it was observed that welding seams obtained by using continuous current formed in a wider area compared to welding seams obtained by using pulsed current. In addition, it became easier to control the weld pool obtained by using pulsed current. Figures 1 and 2 show microstructural images of the samples, joined by using the TIG welding method, at the same magnification rate. While Fig. 1 shows microstructural images of weld metal and transition zone of the samples welded by using continuous current, Fig. 2 shows microstructural images of weld metal and transition zone of the samples welded by using pulsed current.

Examining the microstructural images of the samples welded by using continuous current in Fig. 1, it was observed that grains in weld metal formed as coarse dendrites, the alpha-aluminium grains (white zones) were dominant in the structure due to the effect of the additional metal, and there was a small amount of aluminium silicon eutectic around these 

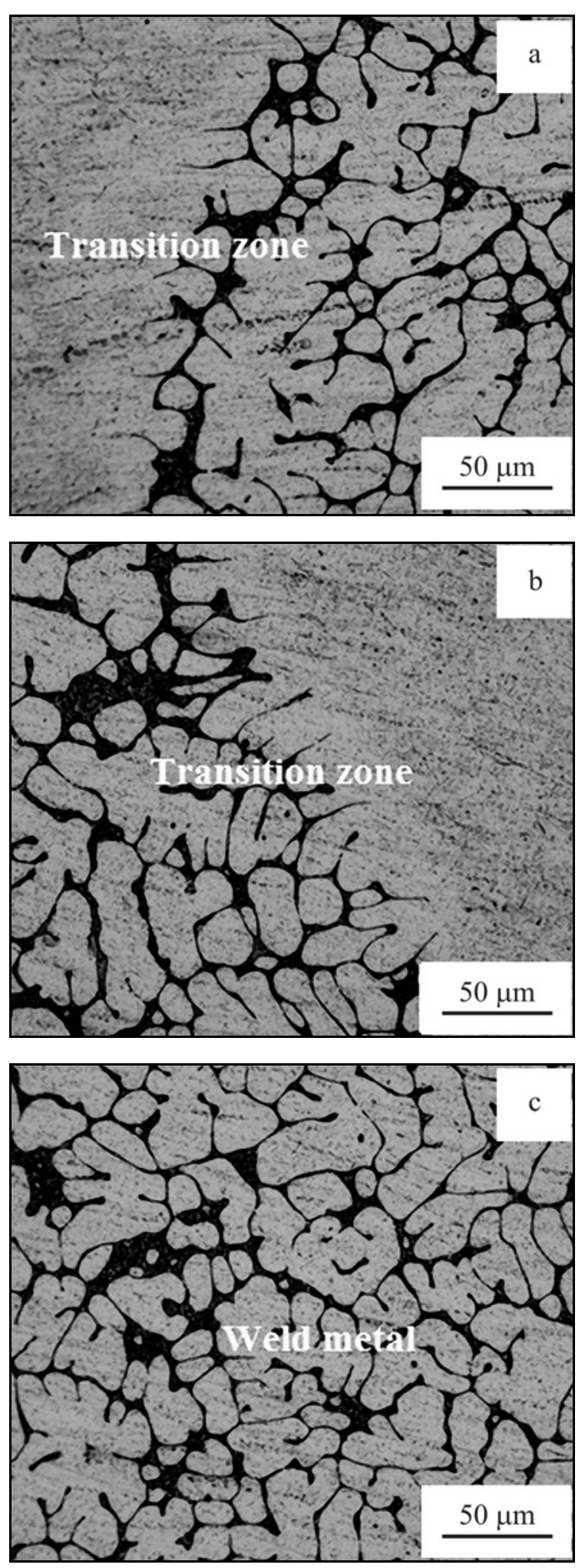

Fig. 1a,b,c. Microstructure pictures of the samples welded with continuous current.

grains. The reason behind why those grains formed in the weld metal were coarse may be that the weld pool formed in a wider area due to high heat input
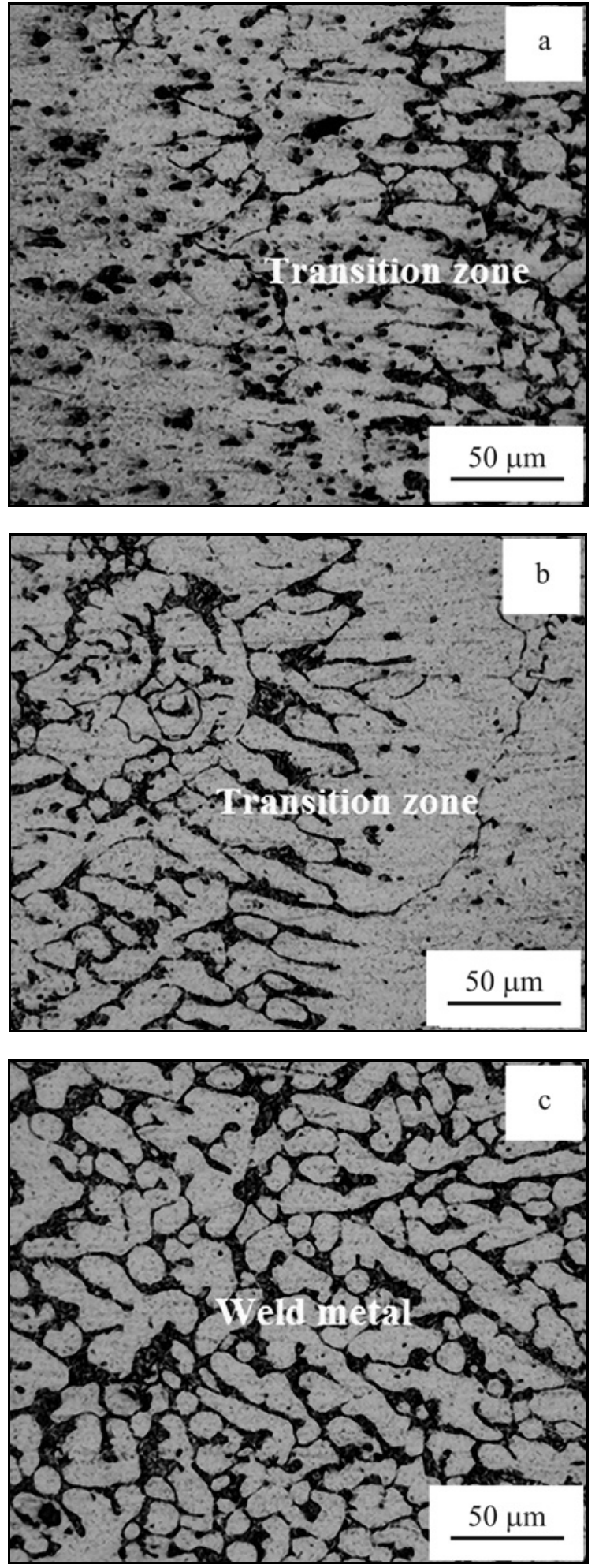

Fig. 2a,b,c. Microstructure pictures of the samples welded with pulsed current.

$\left(1.68 \mathrm{~kJ} \mathrm{~mm}^{-1}\right)$ and solidification of weld metal occurred for a longer time. It is stated in the literature $[10,11,26,27]$ that grains in welding seams, to which grain refinement is applied, have a coarse and colum- 
Table 2. Tensile test results

\begin{tabular}{lcc}
\hline & Tensile strength (MPa) & Elongation (\%) \\
\hline Base metal & 145 & 12 \\
Continuous current & 89 & 7 \\
Pulse current & 96 & 8 \\
\hline
\end{tabular}

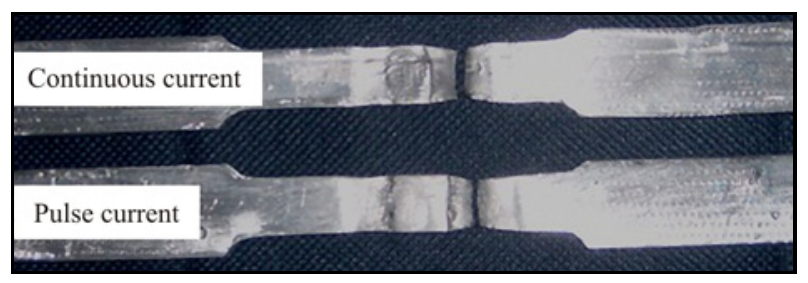

Fig. 3. Tensile test specimens.

nar structure and proceed towards the centre of the welding seam. When microstructural images of weld metal and transition zone of the samples welded by using continuous current were examined, it was observed that a typical weld metal transition zone occurred and the solidification started from the grains of the base metal and proceeded in the form of coarse grains towards the centre of the weld metal.

When microstructural images of the samples welded by using pulsed current in Fig. 2 were examined, it was observed that they had a quite different grain structure compared to grains of weld metal obtained by using continuous current. Considering that the only difference here was the type of current used, it could be seen how the pulsed current was effective on grain structure of weld metal. In the weld metals of the joints welded by using pulsed current, the metal melting under high current (140 A) solidified under low current $(70 \mathrm{~A})$ and thus no adequate time left for grain coarsening. Furthermore, the weld pool formed in a narrower area due to low heat input (average of high and low current) and solidification rate of weld metal was very high. Consequently, the alpha-aluminium grains which formed in the weld metal could not coarsen and became much finer grains compared to grains of the weld metal obtained by using continuous current. These grains were also surrounded by the aluminium silicon eutectic due to the effect of the additional metal. When this phase was compared with the alternative current, it occurred in a more efficient way in the weld metal obtained by using pulsed current. When transition zones of the weld metal obtained by using pulsed current were examined, it was observed that, as for the continuous current, the solidification started from grains of the base metal and proceeded in the form of fine grains towards the centre of the weld metal.
Table 2 illustrates values obtained from the tensile tests applied on the joined samples as a result of the experiments. When the tensile test results in Table 2 were examined, it was observed that the mean tensile strength of the base material which was not joined was $145 \mathrm{MPa}$ and the elongation value was $12 \%$. As a result of the tensile tests applied to the samples welded by using both currents, in all of the samples a fracture was determined at HAZ 4-6 $\mathrm{mm}$ away from the melting border (Fig. 3). In the tensile tests applied to the samples welded by using continuous current, the tensile strength was obtained as $89 \mathrm{MPa}$ by decreasing at the rate of $39 \%$ compared to the base material, and also, the elongation values in tensile samples in the same type of current were obtained as $7 \%$ by decreasing approximately at the rate of $42 \%$. In the joints performed by using pulsed current, tensile test values were determined to be closer to those of the base material compared to the alternative current. In the samples welded by using pulsed current, the tensile strength was obtained as $96 \mathrm{MPa}$ by decreasing at the rate of $34 \%$, and also, the elongation values in tensile samples in the same type of current decreased approximately at the rate of $33 \%$ compared to the base metal and were determined to be $8 \%$. Although in results of tensile tests the effect of grain structure in weld metal on tensile strength could not be commented since fracture did not occur from the weld metals, it could be understood that strength of the weld metal was higher compared to the base material. Heat input applied to materials changed the HAZ properties of the joints depending on the type of current. As is known, high heat input enlarges HAZ. Due to the high heat input in joints welded by using continuous current $\left(1.68 \mathrm{~kJ} \mathrm{~mm}^{-1}\right)$, cooling conditions of welded pieces changed and HAZ formed in a large area. However, because heat input values applied to pieces in samples welded by using pulsed current were quite low compared to continuous current $\left(1.26 \mathrm{~kJ} \mathrm{~mm}^{-1}\right)$, HAZ formed in a narrower area. As is seen from the hardness value results, HAZ hardness values of the joints welded by using pulsed current were higher compared to the joints welded by using continuous current and tensile strength of the samples increased accordingly. Results of the studies conducted on aluminium alloys with different properties $[3,14,28]$ are similar to the results obtained in this study.

Table 3 illustrates hardness values of the base material, additional metal, and weld metal of the pieces welded by using two types of current in the experimental studies. Due to the fine grain structure in the weld metal obtained by using pulsed current, weld metal hardness showed differences compared to the hardness of the weld metal obtained by using continuous current.

When the hardness values in Table 3 were examined, it was observed that while the hardness of the 
Table 3. Microhardness test results $\left(\mathrm{HV}_{0.5}\right)$

\begin{tabular}{lcccc}
\hline Current type & Weld metal & HAZ & Base metal & Filler metal \\
\hline Continuous current & 44 & 38 & 56 & 58 \\
Pulse current & 48 & 41 & & \\
\hline
\end{tabular}

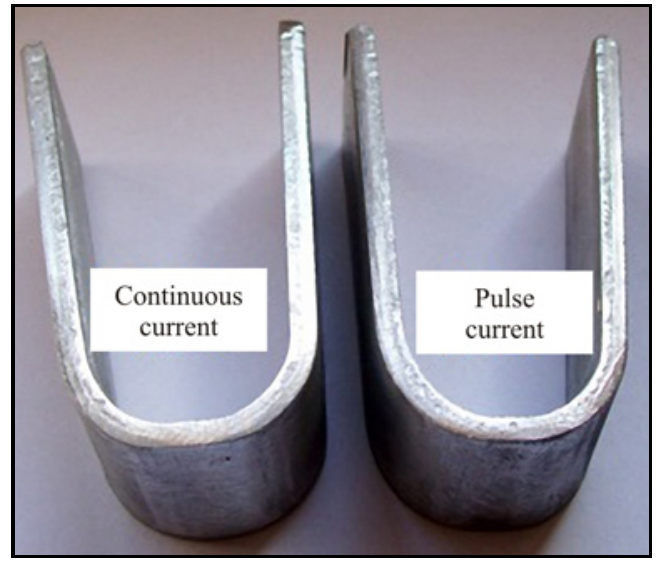

Fig. 4. Bending test specimens.

base material used in the experimental study was 56 $\mathrm{HV}$, the hardness of the additional metal obtained by using wire drawing method was $58 \mathrm{HV}$. The average hardness value of the weld metals of the pieces welded by using continuous current was measured as $44 \mathrm{HV}$, whereas this value was measured as $48 \mathrm{HV}$ in weld metals of the pieces welded by using pulsed current. The alpha-aluminium in the weld metals welded by using continuous current formed coarse dendrites and consequently decreased the hardness value due to the very high heat input and long solidification time. In the weld metals obtained by using pulsed current, alpha-aluminium formed as small and fine grains due to rapid solidification, and also the aluminium silicon eutectic was dominant in the structure due to the effect of the additional metal used. Therefore, hardness values of the weld metals obtained by using pulsed current were higher compared to continuous current. Moreover, as an effect of the heat input applied on welded pieces, HAZ hardness value of the materials welded by using continuous current was found as averagely $38 \mathrm{HV}$, whereas, hardness value was found as approximately $41 \mathrm{HV}$ in HAZ of the materials welded by using pulsed current.

At the end of $180^{\circ}$ bending test applied to the samples welded by two types of current, the visual examinations conducted in transition zones and weld metals of the samples revealed that there was no weld defect such as tearing or crack formation. Figure 4 shows images of the samples that were subject to bending test.

\section{Conclusions}

This study, in which AA 4000 series Al-Si alloy sheets were joined by the TIG welding method using different types of current and microstructure, tensile strength and hardness properties of the joints were investigated, presents the following conclusions:

1. It was determined that heat input applied in joints welded by using pulsed current (due to highampere and low-ampere) was lower compared to continuous current.

2. While welding seams joined by using continuous current in welding of AA 4000 series Al-Si alloy sheets formed in a large area due to an excess of heat input, welding seams obtained by using pulsed current formed in a narrow area and in the view of overlapping centres. Accordingly, it became easier to control the weld pool obtained by using pulsed current.

3. While grains in weld metal formed as coarse dendrites in welding seam obtained by using continuous current, grains in weld metal obtained by using pulsed current were smaller. Consequently, pulse current caused grain refinement in the weld metal.

4. Results of the tensile tests applied on welded samples revealed that joints welded by using pulsed current were more durable than by continuous current due to the change in grain structure depending on heat input applied to pieces.

5. Hardness values of the weld metal obtained by using pulsed current were higher compared to continuous current due to grain structure, heat input, and solidification conditions.

6. Results of the bending tests applied on joints welded by using two types of current revealed that there was no weld defect such as tearing or crack in transition zones and weld metals of the joints.

\section{References}

[1] Praveen, P., Yarlagadda, P. K. D. V., Kang, M. J.: Journal of Materials Processing Technology, 164-165, 2005, p. 1113. doi:10.1016/j.jmatprotec.2005.02.100

[2] Maddox, S. J.: International Journal of Fatigue, 25, 2003, p. 1359. doi:10.1016/S0142-1123(03)00063-X

[3] Balasubramanian, V., Ravisankar, V., Madhusudhan Reddy, G.: Materials \& Design, 29, 2008, p. 492. doi:10.1016/j.matdes.2006.12.015

[4] Gourd, M. L.: Principles of Welding Technology. Oxford, Butterworth-Heinemann Title 1995. 
[5] Juang, S. C., Tarng, Y. S.: Journal of Materials Processing Technology, 122, 2002, p. 33. doi:10.1016/S0924-0136(02)00021-3

[6] Cary, H. B.: Modern Welding Technology. 2nd Edition. Miami, AWS 1981.

[7] Shelwatker, D. A., Madhusudhan Reddy, G., Gokhale, A. A.: Science and Technology of Welding and Joining, 7, 2002, p. 352. doi:10.1179/136217102225006787

[8] Durgutlu, A., Findik, T., Gülenç, B., Çevik, B., Kaya, Y., Kahraman, N.: Practical Metallography, 52, 2015, p. 627. doi:10.3139/147.110352

[9] Senthil Kumar, T., Balasubramanian, V., Sanavullah, M. Y.: Materials \& Design, 28, 2007, p. 2080. doi:10.1016/i.matdes.2006.05.027

[10] Kou, S., Le, Y.: Welding Journal, XII, 1986, p. 65.

[11] Suresh, M. V., Vamsi Krishna, B., Venugopal, P., Prasad Rao, K.: Science and Technology of Welding and Joining, 9, 2004, p. 362. doi:10.1179/136217104225012238

[12] Senthil Kumar, T. Balasubramanian, V., Sanavullah, M. Y.: Materials \& Design, 28, 2007, p. 2080. doi:10.1016/j.matdes.2006.05.027

[13] Ghosh, P. K., Dorn, L., Hübner, M., Goyal, V. K.: Journal of Materials Processing Technology, 194, 2007, p. 163. doi:10.1016/j.jmatprotec.2007.04.113

[14] Balasubramanian, V., Jayabalan, V., Balasubramanian, M.: Materials \& Design, 29, 2008, p. 1459. doi:10.1016/j.matdes.2007.07.007

[15] Babu, S., Senthil Kumar, T., Balasubramanian, V.: Transactions of Nonferrous Metals Society of China, 18, 2008, p. 1028. doi:10.1016/S1003-6326(08)60176-4

[16] Razal Rose, A., Manisekar, K., Balasubramanian, V., Rajakumar, S.: Materials \& Design, 37, 2012, p. 334. doi:10.1016/j.matdes.2012.01.007
[17] Sundaresan, S., Janaki Ram, G. D., Madhusudhan Reddy, G.: Materials Science and Engineering A, 262, 1999, p. 88. doi:10.1016/S0921-5093(98)01010-7

[18] Praveen, P., Yarlagadda, P. K. D. V., Kang, M. J.: Journal of Materials Processing Technology, 164-165, 2005, p. 1113. doi:10.1016/j.jmatprotec.2005.02.100

[19] Zhang, S., Jiang, F., Ding, W.: Materials Science and Engineering A, 490, 2008, p. 208. doi:10.1016/j.msea.2008.01.033

[20] Palani, P. K., Murugan, N.: Journal of Materials Processing Technology, 172, 2006, p. 1. doi:10.1016/j.jmatprotec.2005.07.013

[21] Laiping, L., Shanben, C., Tao, L.: Materials Science and Engineering A, 394, 2005, p. 320. doi:10.1016/j.msea.2004.11.063

[22] Correa, E. O., Costa, S. C., Santos, J. N.: Journal of Materials Processing Technology, 209, 2009, p. 3937. doi:10.1016/i.jmatprotec.2008.09.008

[23] Balasubramanian, M., Jayabalan, V., Balasubramanian, V.: The International Journal of Advanced Manufacturing Technology, 39, 2008, p. 474. doi:10.1007/s00170-007-1233-3

[24] Balasubramanian, M., Jayabalan, V., Balasubramanian, V.: The International Journal of Advanced Manufacturing Technology, 35, 2008, p. 852. doi:10.1007/s00170-006-0763-4

[25] Yu, H., Xu, Z., Fan, Z., Zhao, Z., Li, C.: Materials Science and Engineering A, 561, 2013, p. 259. doi:10.1016/j.msea.2012.11.015

[26] Durgutlu, A.: Journal of Polytechnic, 10, 2007, p. 271.

[27] Durgutlu, A., Gülenç, B., Tülbentçi, K.: Turkish Journal of Engineering \& Environmental Sciences, 23, 1999, p. 251.

[28] Durgutlu, A., Kahraman, N., Gülenç, B.: Journal of Polytechnic, 11, 2008, p. 339. 